\title{
Characterisation and Rehabilitation of One of the Historical Buildings of the Polotsk Campus of the Polotsk State University
}

ByYahor Lazouski, Aliaksandr Paprauka, Dzmitry Lazouski, Aliaksandr Bakatovich

BookNondestructive Techniques for the Assessment and Preservation of Historic Structures

Edition1st Edition

First Published2017

ImprintCRC Press

\section{Pages10}

\section{eBook ISBN9781315168685}

\section{ABSTRACT}

The architectural ensemble of the Polotsk Jesuit Collegium is an eighteenth-century monument of late Baroque architecture. One of its masonry buildings has been almost totally damaged over its lifetime. In this chapter, the authors present their practical experience in the field of surveying, characterisation and rehabilitation of this building (one of the PSU Polotsk campus houses, which is in the ensemble of buildings of the ancient Jesuit Collegium). The technical survey of the masonry walls of the building revealed that they had suffered damage. Furthermore, hidden damage was found in the masonry walls during the reparation and survey work. The technical survey of the soils of the building foundation by ground-penetrating radar sensing revealed a difference of the density characteristics of the foundation soils. Thus, after the reconstruction and restoration of the housing ' $\mathrm{Z} h$ ' building, it is now being used for housing on the Polotsk campus of the Polotsk State University. 